\title{
Investigate the effect of lift-off on eddy current signal for carbon steel plate
}

\author{
Moneer A Faraj ${ }^{1}$, Fahmi Samsuri ${ }^{1, *}$, Ahmed N AbdAlla ${ }^{2}$, Damhuji Rifai ${ }^{3}$, Kharudin Ali $^{3}$ \\ and $Y$. Al-Douri ${ }^{4}$ \\ ${ }^{1}$ Faculty of Electrical and Electronics, University Malaysia Pahang, Malaysia \\ ${ }^{2}$ Faculty of Electronic and Information Eng., Huaiyin Institute of Technology, Huai'an, Jiansu, China \\ ${ }^{3}$ Faculty of Electrical and Automation Engineering Technology, TATI University College, Malaysia \\ ${ }^{4}$ Nanotechnology and Catalysis Research Center (NANOCAT), University of Malaya, 50603 Kuala \\ Lumpur, Malaysia
}

\begin{abstract}
In this study, the effect of various factors like lift-off and depth defect on the eddy current signal was investigated. Investigation methods like response surface methodology (RSM) and composed central design (CCD) were employed to establish the relationship between lift-off distance, depth of a defect and the eddy current signal by the two-factor interaction equation, and would provide a reference in further to accurate the depth defect. The regression analysis suggested that eddy current signal was well fitted by the two-factor interaction equation $(\mathrm{R} 2=0.9656)$. The eddy current signal was investigated by varying the levels of these two independent variables, in which all have significant influences on eddy current signal. There would be a change in the amplitude and when lift-off distance is altered, and lift off distance increased, the increase of the amplitude of output signal decrease gradually.
\end{abstract}

\section{Introduction}

Non-destructive testing (NDT) plays an important role in inspection of structural integrity of materials through detection and sizing of flaws. It is important to detect flaws in the materials at the early stage to prevent catastrophic failure $[1,2]$. Many material inspection methods have been reported in the reviewed literature, including magnetic flux leakage [3], ultrasonic [4] and acoustic [5]. Among these NDT methods, eddy current (EC) technique is preferred for testing of electrically conducting ferromagnetic and non-ferromagnetic materials because of its versatility, No need require any mechanical contact between the ECT probe and the test object, ease of operation and high sensitivity. In EC testing, small changes in impedance of a coil due to distortion of induced eddy currents at flaw regions are measured. In addition, by amending the frequency of the excitation current, the inspection depth can be adjusted [6].

Many researchers investigate many factors that affect the Eddy Current sensitivity, the one factor is the temperature of the material under inspection, which produces variations in material properties like the conductivity and the permeability of material. The ECT method

\footnotetext{
*Corresponding author: fahmi@ump.edu.my
} 
is in general limited to detect the flaws within a depth of $5.0 \mathrm{~mm}$ due to the exponential decay of eddy currents [7]. Although, lowering of excitation frequency enhances the depth of penetration of eddy currents [8]. However the ECT methods detect variations in the magnetic field using coil which are fundamentally limited by their poor sensitivity at low frequencies weak strength of the magnetic fields limits the detection sensitivity of coils for deep flaws $(>5.0 \mathrm{~mm})[9]$. At significant lift-off, no detectable emf will be induced in the secondary coil due to the sample $[10,11]$. This effect is particularly prominent when using sinusoidal excitations, which lose sensitivity beyond $5 \mathrm{~mm} \mathrm{[12].} \mathrm{Although} \mathrm{it} \mathrm{is} \mathrm{not} \mathrm{required} \mathrm{to} \mathrm{have} \mathrm{a}$ zero lift-off, it is imperative to try and maintain a consistent lift-off since the variation in coupling between probe and test piece will significantly affect the received signal.

The present study deals with the eddy current signal analysis using the differential commercial probe (Eg phasec) to inspect the carbon steel plate with dimensions of $260 \mathrm{~mm}$ (length) $\times 10 \mathrm{~mm}$ (height) $\times 30 \mathrm{~mm}$ (width), with three artificial depth defects of varying depths from $1.0 \mathrm{~mm}$ to $3.0 \mathrm{~mm}$ were located parallel to the length of the block. The influences of lift-off and depth defect on eddy current signal were investigated using composed central design (CCD). Finally, the interactive effect of these factors on eddy current signal was analysed by response surface plots, respectively.

\section{Method and material}

\subsection{Testing sample}

The carbon steel block is used similar way of [13],to get the relationship between the physical dimension of the machined cracks and the response of the eddy current testing. The calibration block of carbon steel with dimensions of $260 \mathrm{~mm}$ (length) $\times 30 \mathrm{~mm}$ (width) $\times 10$ $\mathrm{mm}$ (height) was used. The electrical discharge machining (EDM) is used to cut the surface and subsurface depth of slots of artificial defects with depths $1 \mathrm{~mm}, 2 \mathrm{~mm}, 3 \mathrm{~mm}$ depths were produced by performing electrical discharge machining as shows in Figure 1. The material conductivity of carbon steel is $3.18 \%$ of the International Annealed Copper Standard.

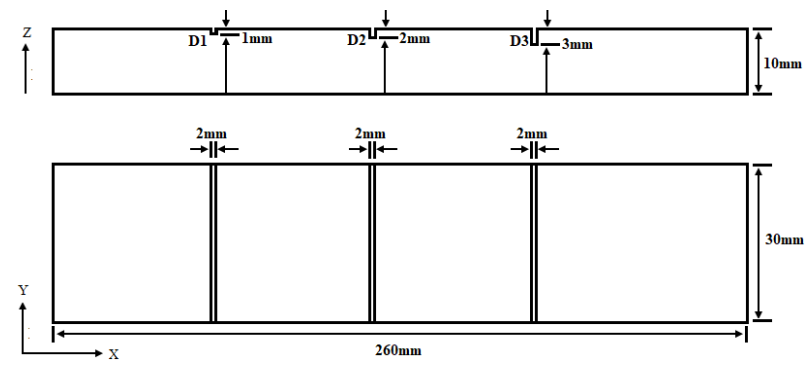

Fig. 1. Front and top views of the carbon steel calibration block

\subsection{Experimental designing}

The Design expert @ version 7.0.0 was used to designing the experiment, drawing RSM plots and analysis of data statistically. The central composite design (CCD) is applied to examine the lift-off and depth defect effect factors on the eddy current testing and investigate the interactive effect of the factors [14]. The eddy current signal was selected as the response variable, while the lift-off (X1) and depth defect (X2) as two independent variables as shown in Table 1. The analysis of variance (ANOVA) was applied to examine the significant of fitting model for experimental values and interactive term. Effect of factors with central 
points and corresponded interactions was investigated by perturbation plots and response surface plots respectively. $\mathrm{F}$ ratio for the models ascertained less than 0.05 to ensure the fitting model reflects and appropriate for response prediction to the system [9].

Table 1. Levels of independents variables for RSM

\begin{tabular}{|c|c|c|c|}
\hline $\begin{array}{c}\text { Independent } \\
\text { Variable }\end{array}$ & Factor & Low Level & High Level \\
\hline X1 & Lift-off (mm) & 0 & 4 \\
\hline X2 & Depth Defect (mm) & 1 & 3 \\
\hline
\end{tabular}

\section{Result and dissection}

Inspection of carbon steel plate with dimensions of $260 \mathrm{~mm}$ (length) $\times 30 \mathrm{~mm}$ (width) $\times 10$ $\mathrm{mm}$ (height) was executed by utilizing a (Eg phasec) differential probe with frequency of 100 $\mathrm{kHz}$ and the phase is set to 12 o'clock with $100 \%$ full screen height (FSH) were the amplitude of a signal is described by how high it is relative to the height of the screen. The EC probe is scanned over the surface of the carbon steel plate in the X direction with a lift-off $0 \mathrm{~mm}$. The variations in amplitude of eddy current signal across the flaws D1 to D3 are shown in Figure 2. It is observed that, the amplitude of eddy current signal increases with the increase in depth of the flaw. The peak amplitude of the differential probe was shown the actual signal is high during $0 \mathrm{~mm}$ lift-off the signal produce is clear.

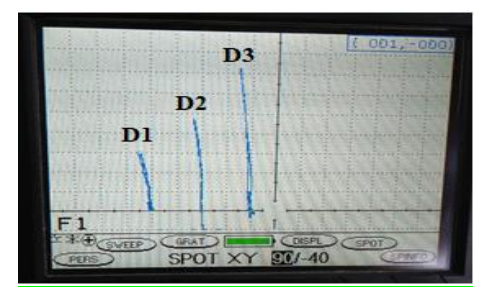

Fig. 2. Variation in percentage amplitude of EC signal across the flaws of varying depths

The measured amplitude signal of EC from the surface flaws in the presence of lift-off varying as $1.0 \mathrm{~mm}, 2.0 \mathrm{~mm}, 3.0 \mathrm{~mm}$ and $4.0 \mathrm{~mm}$ by using the coating shield thickness are shown in Figure 3. The Figure shows the reduction in amplitude signal of EC for is observed when increase the lift-off. This is attributed to the large reduction in magnetic coupling between EC probe and object surface at different lift-off. In addition, Software "Designexpert7.0.0" was used to set the series experiment of 15 runs as shown in Table 2, where two variables were varied at different levels and \% amplitude signal was investigated as response.

Analysis of variance (ANOVA) suggested that response surface for $\%$ amplitude signal is well fit for a two-factor interaction model with an F-value of 102.84 (Table 3). The model F-value of 102.84 implies the model is significant. There is only $0.01 \%$ chances that an Fvalue large because of noise.

The multiple regression analysis of experimental values, following the two-factor interaction equation was suggested to explain the \% amplitude signal of EC (Equation 1).

$$
Y=+6.58667-1.08000 * X_{1}+25.61000 * X_{2}-3.73000 * X_{1} * X_{2}
$$

Where, $Y$ represents the \% amplitude signal yield and $X_{1}$ and $X_{2}$ are the value of lift-off and depth defect respectively. When the \% signal and the lift-off are known. Therefore, Equation 1 would provide a reference for further research of accurate the depth defect. 


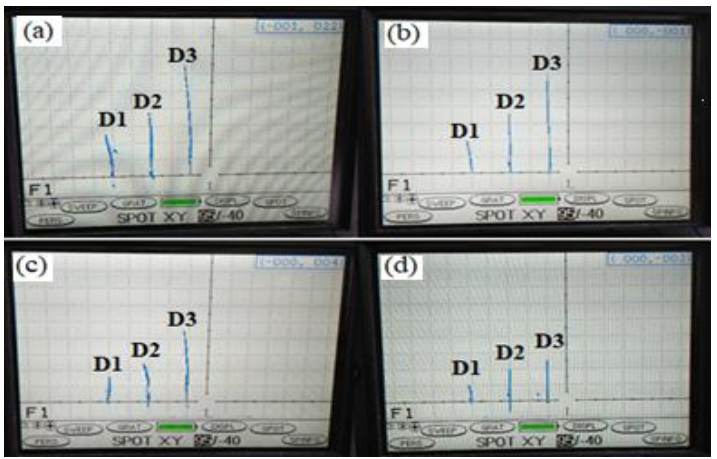

Fig. 3. Variation in percentage amplitude signal of $E C$ across surface flaws under various lift-off condition. (a) $1 \mathrm{~mm}$ Lift-off (b) $2 \mathrm{~mm}$ Lift-off, (c) $3 \mathrm{~mm}$ Lift-off, (d) $4 \mathrm{~mm}$ Lift-off.

Figure 4 shows the three-dimension response surface plots and contour plots which allow a pairwise comparison of variable effect on the \% amplitude signal. The maximum $\%$ amplitude signal of $81 \%$ was observed at maximum and minimum levels variables.

Table 2. Central Composite design with two independent variables and one response (Actual)

\begin{tabular}{|c|c|c|c|}
\hline Run & $\begin{array}{c}\text { Factor A } \\
\text { Lift-off }\end{array}$ & $\begin{array}{c}\text { Factor B } \\
\text { Depth Defect }\end{array}$ & $\begin{array}{c}\text { Response \% } \\
\text { Amplitude Signal }\end{array}$ \\
\hline 1 & 0 & 1 & 34 \\
\hline 2 & 0 & 2 & 54 \\
\hline 3 & 0 & 3 & 81 \\
\hline 4 & 1 & 1 & 29 \\
\hline 5 & 1 & 2 & 43.9 \\
\hline 6 & 1 & 3 & 72.3 \\
\hline 7 & 2 & 1 & 23.2 \\
\hline 8 & 2 & 2 & 40.2 \\
\hline 9 & 2 & 3 & 67.4 \\
\hline 10 & 3 & 1 & 19.4 \\
\hline 11 & 3 & 2 & 30.7 \\
\hline 12 & 3 & 3 & 51.9 \\
\hline 13 & 4 & 1 & 12.9 \\
\hline 14 & 4 & 22.4 & \\
\hline 15 & 4 & 3 & \\
\hline
\end{tabular}


Table 3. ANOVA for Response Surface two-factor interaction (2FI) model

\begin{tabular}{|c|c|c|c|c|c|c|}
\hline Source & $\begin{array}{c}\text { Sum of } \\
\text { Squares }\end{array}$ & df & $\begin{array}{c}\text { Mean } \\
\text { Squares }\end{array}$ & F-value & $\begin{array}{c}\text { P-value } \\
\text { Prob>F }\end{array}$ & Remarks \\
\hline Model & 5760.43 & 3 & 1920.14 & 102.84 & $<0.0001$ & Significant \\
\hline A-Lift-off & 2187.95 & 1 & 2187.95 & 117.19 & $<0.0001$ & Significant \\
\hline $\begin{array}{c}\text { B=Depth } \\
\text { defect }\end{array}$ & 3294.23 & 1 & 3294.23 & 176.44 & $<0.0001$ & Significant \\
\hline AB & 278.26 & 1 & 278.26 & 14.90 & 0.0027 & Significant \\
\hline Residual & 205.38 & 11 & 18.67 & 2 & & \\
\hline Cor Total & 5965.81 & 14 & & 3 & & \\
\hline
\end{tabular}

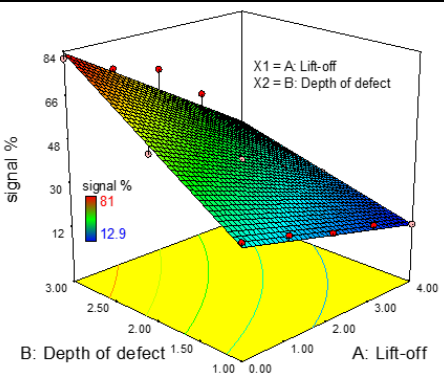

(a)

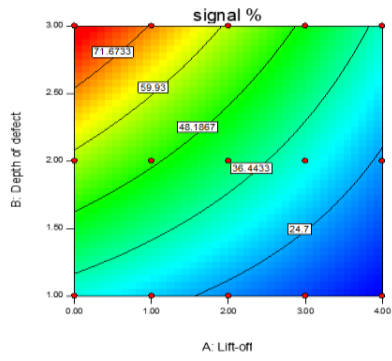

(b)

Fig. 4. Effect of lift-off and depth defect (a) Response surface plot (b) Its contour plot for $\%$ signal:

The percentage of error rate can be calculated by following the Equation 2. The signal produces decrease according to the distance between the sample and the probe, and when the depth of crack is high, then the signal generated is high as can be seen in Table 4.

$\%$ of error rate $=(\%$ Actual signal without lift-off - \%Signal Measured with lift-off $)$

Table 4. The \% Signal for EC with different lift-off and depth defect

\begin{tabular}{|c|c|c|c|}
\hline Lift-off & Depth of defect & Measured signal \% & \% Error \\
\hline 0 & 1 & 34.0 & 0 \\
\hline 0 & 2 & 54.4 & 0 \\
\hline 0 & 3 & 81.0 & 0 \\
\hline 1 & 1 & 29.4 & 4.4 \\
\hline 1 & 2 & 43.9 & 10.7 \\
\hline 1 & 3 & 72.3 & 8.7 \\
\hline 2 & 1 & 23.2 & 10.8 \\
\hline 2 & 2 & 40.2 & 14.2 \\
\hline 2 & 3 & 67.4 & 13.6 \\
\hline 3 & 1 & 19.4 & 14.6 \\
\hline 3 & 2 & 30.7 & 23.7 \\
\hline 3 & 3 & 51.9 & 29.1 \\
\hline 4 & 1 & 12.9 & 21.1 \\
\hline 4 & 2 & 22.4 & 32.4 \\
\hline 4 & 3 & 27.8 & 53.2 \\
\hline
\end{tabular}




\section{Conclusion}

In this paper response surface methodology is used to investigate the amplitude signal of EC at various levels of lift-off and depth defect. It is shown that the amplitude signal of EC signal is increasing gradually as depth defect distance increased, however, the increase of amplitude of EC signal decrease gradually when lift off distance increased. The relationship between lift-off, depth defect and the \% amplitude signal is established by the two-factor interaction equation which provide a reference in further to accurate the depth defect. The future work on use of the compensation technique to eliminate the impact of lift-off to get the accuracy depth defect reading.

The authors acknowledge Universiti Malaysia Pahang (UMP) for supporting the research through the RDU 170379 grant.

\section{References}

1. M. Faraj, S. Fahmi, R. Damhuji, and A. Kharudin, Indian Journal of Science and Technology.10, 1-5 (2017).

2. K. B. Ali, A. N. Abdalla, D. Rifai, and M. A. Faraj, IET Circuits, Devices \& Systems, (2017).

3. A. J. Lynch, Rice University, (2009).

4. W. Deutsch, P. Schulte, M. Joswig, and R. Kattwinkel, European Conference for Nondestructive Testing, (2006).

5. O. Hunaidi and W. T. Chu, Applied Acoustics 58, 235-254 (1999)

6. M. A. Faraj, F. Samsuri, and A. N. AbdAlla, Journal of Telecommunication, Electronic and Computer Engineering 10, 7-11 (2018).

7. B. Sasi, V. Arjun, C. Mukhopadhyay, and B. Rao, Sensors and Actuators A: Physical, 275, 44-50 (2018).

8. J. García-Martín, J. Gómez-Gil, and E. Vázquez, Sensors 11, 2525-2565 (2011).

9. D. Rifai, A. N. Abdalla, R. Razali, K. Ali, and M. A. Faraj, Sensors, 17, 579 (2017).

10. G. Mook, O. Hesse, and V. Uchanin, Materials Testing 49, 258-264 (2007).

11. S. G. Mokros, P. R. Underhill, J. E. Morelli, and T. W. Krause, IEEE Sens. J 17, 444449, (2017).

12. C. Davies, ed: Google Patents, (2004).

13. R. Porto, V. Brusamarello, R. Azambuja, and O. Frison, Sensing Technology (ICST), 2013 Seventh International Conference, 424-429 (2013).

14. M. A. Faraj, F. Samsuri, A. N. Abdalla, D. Rifai, and K. Ali, Applied Sciences 7, 668, (2017). 